\title{
A tribute to the life and work of George W. Wetherill: Some reflections of his career at DTM
}

\author{
Douglas O. ReVelle \\ Los Alamos National Laboratory, Los Alamos, New Mexico, USA \\ email: revelle@lanl.gov
}

George Wetherill and I worked together as scientific collaborators when I was a postdoctoral fellow in 1977-1978 at the Department of Terrestrial Magnetism (DTM) of the Carnegie Institution of Washington (CIW) in Washington, D.C. We worked on problems of meteoroids interacting in Earth's atmosphere along with Richard McCrosky at Harvard College Observatory and Zdeněk Ceplecha at the Ondřejov Observatory in Czechoslovakia and also with Sundar Rajan who had already arrived at DTM from the University of California at Berkeley before me.

George had just returned from being the Chairman of the Planetary and Space Science Department at UCLA and while there was on the governing board that proposed the creation of the IGPP (Institute of Geophysics and Planetary Physics) at the National Laboratories including Los Alamos where I have been ever since January 1994. His direct intent and interest in my being an Astronomy postdoctoral fellow at DTM was evident from even before I arrived at DTM.

One day I phoned him to confirm that everything was prepared for my arrival at DTM and he acted very odd to me on the phone. It turns out that Dr. Vera Rubin was in his office lobbying for a extragalactic astronomer postdoctoral position, but George had already made up his mind to have me at DTM so he let Vera have her say completely and then told her I was coming and that was that. Later on that day he just called me back as if the other conversation hadn't happened and told me that I should plan to arrive at DTM very soon. I found out about my officially being called an Astronomy postdoctoral fellow about a year later when Professor Bart Bok came to give a seminar on the origin of Bok Globules. I was listed on an official postdoctoral list that had recently been assembled as being an Astronomy postdoc much to my surprise since all of my degrees are in Atmospheric and Oceanic Sciences or Aeronomy and Planetary Atmospheres.

At least in those days DTM was very lively and always being visited by dignitaries such as Bok and many others. Pictures on the wall of Niehls Bohr were evident in the staff library and office (of the director's secretary) which I loved to use which had many wooden book shelves and wonderful sets of books and journals. Many times we would have 3-4 seminars in one week for the scientific staff's fields of Classical and Solar System Astronomy, Geophysics and Seismology, Geochemistry and of Nuclear Physics.

George was always mostly very friendly, but also very intense. When we met for the last time years later at the Cornell ACM in 1999 (see below), he had changed quite a bit and was much more social and willing to have several beers together, etc. His first wife, Phyllis, had passed away and I think he really missed the "good" old days together with the solar system Astronomy postdoctoral fellows, etc. at DTM. He almost never took breaks from his almost 12 hour days at DTM and rarely drank coffee or even water or participated in the "lunch" club that had been formed there since the original DTM chef and his staff had left for more fertile pastures (the chef just cost too much to keep on in 
the 1960's and beyond). One day while we were playing volleyball in preparation for the big game against the geophysical lab (which has since moved onto the same site at 5241 Broad Branch Road near Chevy Chase Circle in Washington, D.C.), George came out of his office and made a rare appearance on his veranda to the entire postdoctoral group. He politely reminded us of the need to go back to work and not just to play games, but it was all in good fun and we certainly worked harder after the great exercise as I remember it or at least I know that I worked even harder.

One day in the Spring of 1978 George and other senior DTM staffers asked me to show our new secretary Maura around DTM to help get her oriented to the buildings and offices. In order to illustrate George's full intensity, I recall a drinking fountain episode that occurred at DTM as Maura began working for the Carnegie Institution of Washington (this story was also told by me in front of his many DTM colleagues at George's DTM retirement party many years later). George's office was on the southern end of the third floor of DTM. There were standard drinking fountains present only on the first and third floors at the top of the main hallway through the three story structure. Maura and I had just examined the room where "glass slides" were still being made and were going up to the third floor from the first floor, but while we briefly stood at the landing between the second and third floors, we observed the following: George got up from his desk and walked directly toward the stairwell and proceeded down to the second floor. He walked right by the drinking fountain on his own floor on the way down the stairs. When he reached and had passed us on the second floor he proceeded to bend over at the spot where the drinking fountain would have been found on the first and third floors and "pushed" the nonexistent button down on the nonexistent drinking fountain and decidedly drank until he was completely satisfied from the nonexistent fountain. Maura looked directly at me and immediately said "That's my new boss?" George's response to my comments at his retirement dinner in D.C. several years ago was "Well, I am here and I am still ok anyway."

As yet another illustration of his scientific intensity, I will relate the story of his dosages of "Wetherillitis" to me (as my wife Ann liked to call them since I always came home completely drained mentally on those inevitable days), our monthly 12 hour meetings with no breaks in 1977-1978. Again the intensity of his purpose was thoroughly evident in these very intense meetings. George had the habit of dragging out all that his collaborators had been working on for the past month or so at such meetings. We would first make a list of topics that we were both working on and where our various lines of thought intersected. The various meteoroid related topics that we usually discussed are listed later on. After many many tiring hours of converging towards a consensus of where we should be heading scientifically over the next month or so we would finally begin to relax and be positive about what had already been done. On one occasion late in the day George's first wife, Phyllis, arrived at our meeting place in his office. I was finally summarizing everything for the day's efforts and was almost finished as she entered the room. George almost instinctively jumped up and put on his coat and was out the door in a flash and I was still talking. They left almost as quickly as she had entered and I slowly rose and put on my jacket and gathered my things for my long ride home to Culpeper, Virgina (some 85 miles away from D.C.). After another day of "Wetherillitis", I almost looked forward to these long drives! We were nonetheless able to get an enormous number of things done during these sessions and finally wrote two major scientific papers together as well as submitted and subsequently presented numerous meeting abstracts (at the DPS of the AAS, the Meteoritical Society, AGU, ASA, etc.).

George helped me immensely in my interactions with Zdeněk Ceplecha and the staff of the Ondrejov Observatory through a U.S. National Academy of Sciences Scientific 
Exchange grant for 8 weeks in the summer of 1980. Dr. Zdeněk Ceplecha, the Chief of the Interplanetary Matter Department for many years at the Ondrejov Observatory, was even then a very well known world leader in the science of meteors. Since this all happened before email and the multitude of personal computers that we have today at our disposal, numerous and very lengthy letters were being written back and forth across the Atlantic often taking 4-8 weeks each way due to the Communist government in Czechoslovakia.

George recognized the vital interaction that needed to take place between Ceplecha and myself and saw to it that this connection was fostered. This work culminated in the Spring of 1983 when Zdeněk was awarded the U.S. National Academy of Sciences Prize, the George P. Merrill Award, and Zdeněk was invited to receive the prize at their offices in Washington D.C. Again with George's help I was made financially able to come to the award ceremony and be with Ceplecha during his time in the U.S. when great honors were being bestowed upon him.

During his early and teenage years George was infatuated with the daughter of the great classical meteor physicist Dr. Charles P. Olivier while growing up in his native Philadelphia. In fact, his fundamental reason for turning to our science of Planetary and Solar System problems were fundamentally instilled by this need to impress the teenage daughter back in the 1920's and 1930's. She of course was not impressed by her father's pursuits much to George's dismay. He retold this story to me at the ACM at Cornell in 1999 while still asking if anyone knew of her whereabouts even then.

Another illustration of George's scientific intensity, in case you still may doubt it, was during our excursion boat trip together with the numerous ACM scientists at Belgirate, Italy in 1993, when George and I spent one and a half hours totally alone onboard the large cruise boat that had been hired for the day on Lake Maggiore in Northern Italy near the Swiss border (we were together for this long time with the exception of the barebones crew of the boat and their mascot dog). Everyone else had departed the boat to shop and sightsee on a well-known tourist excursion island. George and I discussed meteor science intensely during this lengthy period. We never even knew everyone got off the boat until they all returned. Several people later got back on and laughed heartily when they saw that we were both still there and at the very same seats for all that time (and still drinking a fine European beer) discussing what else, but our first loves, science (this tremendous laughter included outbursts from the late Mayo Greenberg and several others as well)!

George is perhaps most well known in our scientific community for his absolutely pioneering effort on discovering the theoretical origins of the terrestrial planets and their formation processes and the huge role played by Jupiter in its protection of the terrestrial planets. Nonetheless all the problems that I collaborated on with George involved our knowledge of meteors and their composition and structure and their orbital associations and their properties as deduced by directly studying their entry into Earth's atmosphere. As an honor for all of his very hard and pioneering efforts, I believe that we as a community should consider bestowing his name on a region of our Solar System, such as that from the outer edge of the asteroid belt to Jupiter's orbit, as the Wetherill zone.

Topics that we collaborated on together while I was at DTM included (from 1977 to 1981, which included return summer visits after my final departure to Arizona in late 1978):

(a) Single-body entry modeling to determine initial masses (through ablation effects) and the initial velocities and orbits of meteorites (with Sundar Rajan);

(b) Luminous efficiency of meteorites (with Sundar Rajan); 
(c) Theoretical predicted mass loss comparisons to cosmic ray tracks measurements in meteorites (with Sundar Rajan);

(d) Identification of meteorites with bright meteors;

(e) Large bolide influx rate determined using microbarographs;

(f) Studies and identification of meteorites from beyond Jupiter;

(g) Impacts of extraterrestrial bodies on the Earth and the Moon.

Some of this work appeared as articles in the Annual Report of the Director of DTM, subsequently became formal papers in Icarus and in the Arizona Comets book of 1981 (L. Wilkening editor), and many of the ideas and concepts were presented at multiple scientific conferences including the Meteoritical Society in both Canada and in Europe (with the latest in 1983).

During some years, George as the DTM Director would pick a poem to add to the mix of papers contained in the Annual Reports that were done back then. It seems appropriate that we should add one of his favorite poems to this tribute to his life and times. In the section entitled Meteorites and Meteoroids in the DTM Annual Report for 1980-1981 you can still find the provocative poem:

.... the might

Of earth-convulsing behemoth, which once

Were monarch beasts, and on the slimy shores

And weed-overgrown continents of earth, Increased and multiplied like summer worms

On an abandoned corpse, till the blue globe

Wrapped deluge round it like a cloak, and they

Yelled, gasped and were abolished; or some God

Whose throne was in a Comet, passed and cried

"Be not!" and like my words they were no more.

Shelley (1820)

When I finally received an offer of university employment at a Physics and Astronomy Department in Arizona the summer of 1978 George's first response to me was: "We can sue them!" and George was referring to the fact that they had offered me employment long after the traditional deadline of May 1st for hiring faculty for the next academic year.

George even offered me a staff position in meteoroids and meteoritics at DTM in 1999 while we were at the ACM at Cornell which would have been quite nice. Very reluctantly I told him that I couldn't even think of that offer as an option because it wasn't possible to make a living in the U.S.A. doing meteoroid research at DTM since I needed the NSF (US National Science Foundation) or some similar organization for my complete funding support. When I first arrived at DTM individual support funding was provided by interest monies on the Carnegie endowment. Later after equipment grants to the NSF were routinely written and funded for technical staff support equipment, the CIW Board of Trustees decided to do the same for CIW staff salaries, a fact which greatly limited my chances to return to DTM.

George ultimately was extremely successful and triumphant in his scientific career. Like most of us, he also had tragedies including the loss of his son. Nevertheless he should be remembered as a great scientist who foresaw the possibilities of the future and made things happen. He will be missed by all of us who knew him well. 